\title{
Experimental Validation of a Finite Element 2D Axial Thomson Coil Model with Inductance and Resistance Compensation
}

DOI:

10.1049/cp.2017.0032

\section{Document Version}

Accepted author manuscript

Link to publication record in Manchester Research Explorer

Citation for published version (APA):

Vilchis-Rodriguez, D., Shuttleworth, R., \& Barnes, M. (2017). Experimental Validation of a Finite Element 2D Axial Thomson Coil Model with Inductance and Resistance Compensation. In The 13th IET international conference on $A C$ and DC Power Transmission (pp. 1-6). [0030] Institution of Engineering and Technology . https://doi.org/10.1049/cp.2017.0032

Published in:

The 13th IET international conference on AC and DC Power Transmission

\section{Citing this paper}

Please note that where the full-text provided on Manchester Research Explorer is the Author Accepted Manuscript or Proof version this may differ from the final Published version. If citing, it is advised that you check and use the publisher's definitive version.

\section{General rights}

Copyright and moral rights for the publications made accessible in the Research Explorer are retained by the authors and/or other copyright owners and it is a condition of accessing publications that users recognise and abide by the legal requirements associated with these rights.

\section{Takedown policy}

If you believe that this document breaches copyright please refer to the University of Manchester's Takedown Procedures [http://man.ac.uk/04Y6Bo] or contact uml.scholarlycommunications@manchester.ac.uk providing relevant details, so we can investigate your claim.

\section{OPEN ACCESS}




\title{
Experimental Validation of a Finite Element 2D Axial Thomson Coil Model with Inductance and Resistance Compensation
}

\author{
D.S. Vilchis-Rodriguez, R. Shuttleworth and M. Barnes \\ School of Electrical and Electronic Engineering, The University of Manchester, M13 9PL, United Kingdom \\ E-mail: damian.vilchis-rodriguez@manchester.ac.uk; roger.shuttleworth@manchester.ac.uk; mike.barnes@manchester.ac.uk
}

Keywords: Hybrid HVDC breaker, Thomson coil, ultra-fast actuator.

\begin{abstract}
This paper assesses the accuracy of a transient 2D axissymmetric FE model of a Thomson coil actuator compared with experimental results. Sources of error in the coil representation are identified and the $2 \mathrm{D}$ model is compensated accordingly for improved accuracy. Experimental results validate the proposed approach and effects of armature bending in the predicted armature velocity are investigated. The analysis presented demonstrates that a 2D FE model with compensation can accurately predict a Thomson coil actuator dynamic behaviour, even when armature bending occurs.
\end{abstract}

\section{Introduction}

The Thomson Coil (TC), is the preferred actuator design for applications that require ultra-fast actuation [1-5]. The TC comprises a planar spiral coil and an electrically conductive solid armature disc, with the armature placed parallel and concentric to the coil, Fig. 1. The TC operates by magnetic repulsion due to induced eddy currents within the armature. Given the relevance of the design for ultra-high speed actuation applications, considerable effort has been put into the development of numerical models to predict accurately actuator behaviour [6-11]. FEA software has been shown to provide simulation results where the accuracy of the predicted armature speed decreases with armature velocity increase [12]. Given that a TC has to operate at a very high speed, an analysis of the factors that impact on 2D FE model accuracy is necessary in order to reduce discrepancies. Due to TC symmetry a 2D axis-symmetric model of the coil is assumed to be a good approximation [10-13]. However, geometric differences between model and physical coil may give rise to disparities in inductance and resistance values, resulting in misleading results. For better evaluation of coil inductance a 3D FEA model should be used. However a 3D FE transient simulation of TC operation can be very taxing in terms of simulation time and computer resources. Therefore a 2D model is usually preferred. In this research FE simulations were performed using COMSOL 5.2 multi-physics software. In order to reduce error in the $2 \mathrm{D}$ model a steady state $3 \mathrm{D}$ FEA model of the coil was used to calculate coil inductance and resistance, and the 2D model compensated, by adding passive inductor and resistor components in series with the 2D FE coil model, to account for differences. Experimental results validate the effectiveness of the proposed approach. The effect of armature bending on the measured armature velocity was also investigated, and the $2 \mathrm{D} \mathrm{FE}$ model modified to account for this.

\section{Test System}

Fig. 2 shows a circuit diagram of the TC test-rig used for model validation, and Fig. 3 shows a picture of the experimental set up. The TC planar coil comprises 28 turns of circular cross-section, $3 \mathrm{~mm}$ diameter, enamelled copper wire. The coil has an inner diameter of $4 \mathrm{~cm}$ and is embedded in a circular cavity milled into a $25 \mathrm{~mm}$ Tufnol sheet, and fixed with epoxy resin. The wire diameter, including insulation, was measured as $3.11 \mathrm{~mm}$, therefore the separation gap between consecutive turns is assumed as $0.11 \mathrm{~mm}$. The capacitor bank comprises three parallel connected FELSIC $85 / \mathrm{s}$ electrolytic capacitors, each rated at $450 \mathrm{~V}, 8250 \mu \mathrm{F}$. A high power diode, type VISHAY VS-240U80D, was used for capacitor reverse voltage protection and a SEMIKRON SKKT 162/12E Thyristor to initiate capacitor bank discharge. The capacitance of each capacitor was measured and the ESR obtained from the manufacturer datasheet; maximum datasheet ESR value was used in the simulations. Connection lead resistance and inductance were measured using an Agilent 3442OA Micro Ohm Meter and an Agilent 4294A impedance analyser, respectively. For comparison purposes coil current and capacitor bank voltage were measured during experiments using a Rogowski coil and a differential voltage probe, respectively. The TC armature displacement was recorded using a Photron Fastcam SA-X2 high speed camera at 50,000 fps; covering a fixed visual area of $4 \times 3.5 \mathrm{~cm}$, approximately, at a resolution of $512 \times 432$ pixels. Automatic video tracking software was used to determine the armature's displacement versus time characteristic and armature speed was estimated by numerical differentiation of the armature displacement. A zero-lag running average algorithm was used to condition the armature displacement signal and a smooth noise-robust numerical differentiator was used to calculate armature speed. Table I lists the test system main parameters.

Coil lead outs, the short conductor segments at both ends of the spiral coil that are part of the same piece of wire that the coil but do not follow the planar spiral path (i.e. the straight conductor segments which go from the spiral coil internal and external ends to the points A and B in Fig. 2) are considered separately of the connection leads inductance and resistance values listed in Table I. Coil lead out effects are discussed in more detail in section 3 . 


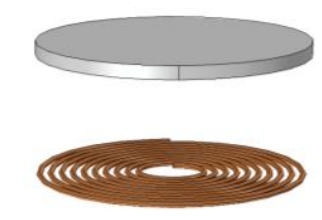

Fig. 1: Thomson coil.

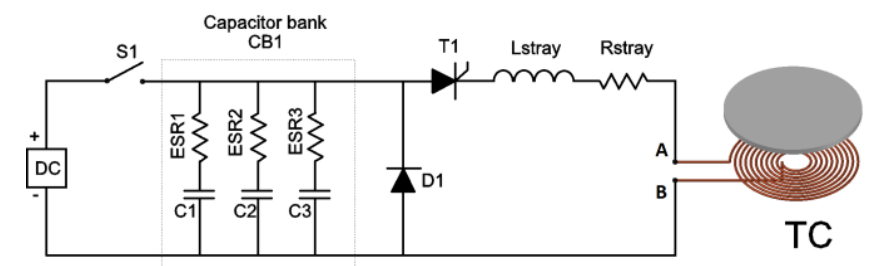

Fig. 2: TC test system diagram.

\begin{tabular}{|l|l|}
\hline Characteristic & Value \\
\hline Turn number & 28 \\
\hline Conductor diameter & $3 \mathrm{~mm}$ \\
\hline Insulation thickness & $0.055 \mathrm{~mm}$ \\
\hline Conductor resistivity & $2.42 \mathrm{~m} \Omega / \mathrm{m} @ 20 \mathrm{C}$ \\
\hline Coil inner diameter (nominal) & $4 \mathrm{~cm}$ \\
\hline Coil outer diameter (nominal) & $22 \mathrm{~cm}$ \\
\hline Capacitor $\mathrm{C}_{1}$ & $10.03 \mathrm{mF}$ \\
\hline Capacitor $\mathrm{C}_{2}$ & $9.95 \mathrm{mF}$ \\
\hline Capacitor $\mathrm{C}_{3}$ & $10.37 \mathrm{mF}$ \\
\hline ESR max. & $20 \mathrm{~m} \Omega$ \\
\hline Thyristor $\mathrm{T}_{1}$ Vdrop & $0.83 \mathrm{~V}$ \\
\hline Thyristor $\mathrm{T}_{1}$ linear resistance & $1.60 \mathrm{~m} \Omega$ \\
\hline Diode $\mathrm{D}_{1}$ Vdrop & $1.10 \mathrm{~V}$ \\
\hline Diode $\mathrm{D}_{1}$ linear resistance & $3.71 \mathrm{~m} \Omega$ \\
\hline Connection leads resistance & $2.98 \mathrm{~m} \Omega$ \\
\hline Connection leads inductance & $1.0 \mu \mathrm{H}$ \\
\hline
\end{tabular}

Table 1: Test system parameters.

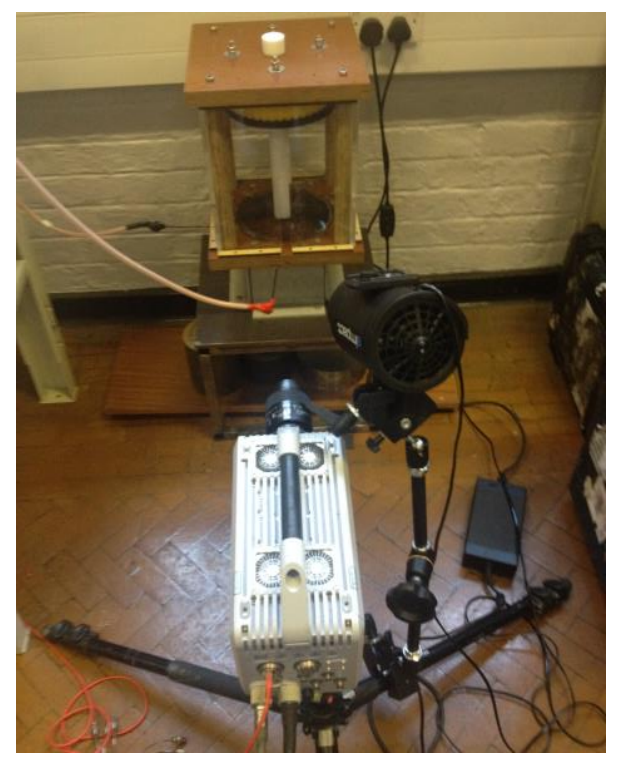

Fig. 3: TC test system setup.

\section{Simulation model}

The system described in section 2 was implemented in COMSOL multi-physics FEA software. In the implementation, the excitation circuit was interfaced with an axis-symmetric FE model of the TC, with the coil placed in the centre of a large air domain. It should be noted that although not strictly axis-symmetric this simplification has been widely used in the research literature [10-13]. For the sake of fidelity each capacitor was considered individually in the simulations. In addition, the high temperature V-I characteristics of the diode and thyristor were used to define voltage drops and equivalent linear resistances in the model excitation circuit. From Table I all coil parameters are known, therefore if any significant difference exists between simulation and experimental results (for coil response only) it may be expected to come from the FE coil representation. Equations (1)-(6) are used by the FE software for the model solution, the corresponding variables are listed in Table 2. The armature is assumed to be built of an infinitely rigid material, thus the mechanical behaviour of the system is simply described by equations (7)-(9).

$$
\begin{array}{r}
\sigma_{e} \frac{\partial A}{\partial t}+J-\sigma_{e} v \times B=J_{e} \\
B=\nabla \times A \\
J=\nabla \times H \\
F_{l}=J \times B \\
\sigma_{e}=\sigma_{e 0}\left[1+\alpha\left(T-T_{0}\right)\right]^{-1} \\
\rho C_{p}\left(\frac{\partial T}{\partial t}+v \cdot \nabla T\right)=\nabla \cdot(k \nabla T)+Q
\end{array}
$$

\begin{tabular}{|l|l|}
\hline Variable & Description \\
\hline $\boldsymbol{B}$ & Magnetic flux density \\
\hline $\boldsymbol{H}$ & Magnetic field intensity \\
\hline $\boldsymbol{J}$ & Current density \\
\hline $\boldsymbol{J}_{\boldsymbol{e}}$ & External current density \\
\hline $\boldsymbol{A}$ & Magnetic vector potential \\
\hline $\boldsymbol{F}_{\boldsymbol{l}}$ & Lorentz force \\
\hline $\boldsymbol{v}$ & Velocity \\
\hline $\boldsymbol{\sigma}_{\boldsymbol{e}}$ & Electric conductivity \\
\hline $\boldsymbol{\sigma}_{\boldsymbol{e}}$ & Reference electric conductivity \\
\hline $\boldsymbol{T}$ & Temperature \\
\hline $\boldsymbol{T}_{\boldsymbol{\theta}}$ & Reference temperature \\
\hline $\boldsymbol{\alpha}$ & Temperature coefficient \\
\hline $\boldsymbol{\rho}$ & Density of the material \\
\hline $\boldsymbol{C}_{\boldsymbol{p}}$ & Heat capacity \\
\hline $\boldsymbol{k}$ & Thermal conductivity \\
\hline $\boldsymbol{Q}$ & Resistive losses \\
\hline $\boldsymbol{t}$ & Time \\
\hline
\end{tabular}

Table 2: FE equations variables. 


$$
\begin{aligned}
& F=m a \\
& a=\frac{d v}{d t} \\
& v=\frac{d u}{d t}
\end{aligned}
$$

where $F$ is total force acting over the armature, $m$ is mass, $a$ is acceleration and $u$ is displacement of the armature, respectively. The total force acting over the armature is given by $(10)$.

$$
F=F_{g}+F_{l}
$$

where $F_{g}$ is gravitational force. The electromagnetic force acting over the armature is calculated by integration of Maxwell's stress tensor over the exterior surfaces of the armature domain using the COMSOL force component. It should be noted that only vertical components of force, displacement, velocity and acceleration are of interest in this analysis. Consequently all results reported in this work are related to the vertical direction only. To assess the accuracy of the axis-symmetric representation of the coil a comparison of measured and predicted coil values was carried out. A 3D FE representation of the coil, and an analytical inductance value, obtained using Wheeler's formula for planar coil inductance (11) [14], were used in the comparisons.

$$
L=\frac{n^{2} r^{2}}{8 r+11 c}
$$

where $n$ is the number of turns, $r$ is the coil mean radius, and $c$ is the coil width in inches. It should be noted that the applicability of (11) is limited when a low turn number is considered [14], otherwise an accuracy within 5\% of measured values can be expected. Given that inductance values obtained using FEA software are susceptible to geometry considerations, a sensitivity analysis was conducted in order to identify simulation parameters that affect FE predicted values. From the sensitivity analysis it was found that FE predicted coil inductance values are sensitive to the surrounding air domain size and boundary conditions. On the other hand, mesh density was found to be relevant to coil resistance prediction. For instance, a large air domain is required to minimize variations in the coil inductance calculated using FEA software. An air region with a diameter four times that of the coil outer diameter and surrounded by an infinite element domain was used in the analysis; further increases in the air domain diameter did not affect significantly the calculated coil inductance. A very fine mesh was applied to the coil to reduce resistance calculation error. Predicted values are compared with measured coil values in Table 3. Coil resistance and inductance were measured using an Agilent 3442OA Micro Ohm Meter and an Agilent 4294A impedance analyser, respectively. Hence measured values include coil lead out effects. Analytical coil resistance was obtained using conductor resistivity and the coil length determined using a CAD software $(11.45 \mathrm{~m})$, lead outs were not considered in the calculation to allow a straight comparison between predicted values.

\begin{tabular}{|l|l|l|l|l|}
\hline Source & $\begin{array}{c}\text { Inductance } \\
{[\boldsymbol{\mu} \mathbf{H}]}\end{array}$ & $\begin{array}{c}\text { Rel. err. } \\
{[\mathbf{\%}]}\end{array}$ & $\begin{array}{c}\text { Resistance } \\
{[\mathbf{m} \boldsymbol{\Omega}]}\end{array}$ & $\begin{array}{c}\text { Rel. err. } \\
{[\mathbf{\%}]}\end{array}$ \\
\hline 2D FE & 84.03 & 5.84 & 27.05 & 5.98 \\
\hline 3D FE & 87.89 & 1.51 & 27.71 & 3.68 \\
\hline Analytical & 86.72 & 2.82 & 27.71 & 3.68 \\
\hline Measurement & 89.24 & ---- & 28.77 & ---- \\
\hline
\end{tabular}

Table 3: Coil inductance and resistance values comparison.

From the values in Table 3 it is evident that the 2D axissymmetric model is the least accurate of the methods used for coil parameter prediction. It should be noted that in previous assessments it has been assumed that (for coil response only) the discrepancies between FE simulations and experimental results mostly came from stray inductance initially neglected in the numerical simulations $[11,12]$, with typical values of around $1 \mu \mathrm{H}$. The analysis here demonstrates that the assumption of coil axial symmetry may be a larger source of error. From the results in Table 3 it is also clear that the $3 \mathrm{D}$ FE model provides the most accurate prediction of inductance value. Thus, in the absence of measurements the inductance value obtained using a stationary 3D FE model may be used as reference. Furthermore the 3D model allows the inclusion of lead effects. For coil resistance the analytical dc resistance can be used as reference, since this is immune to mesh size and other geometric considerations. In this paper the differences between predicted coil inductance and resistance values obtained using the 2D and 3D FE models are used for passive compensation of the 2D model: a resistor and an inductor, that account for the differences, are connected in series with the 2D axial representation of the coil. Thus frequency, thermal and other non-linear effects are neglected in these added passive elements. Passive compensation is a feasible approach given the linear nature of the TC magnetic circuit and relatively small compensation values. Coil lead out effects were also considered in the simulations. For instance, coil lead out length was measured as $47 \mathrm{~cm}$, therefore an additional $1.13 \mathrm{~m} \Omega$ in compensation were incorporated to account for its effect. On the other hand, based on stationary 3D FE simulations, coil lead out inductance was found to be negligible.

\section{Model verification}

Based on the analysis in section 2, the 2D FE model was compensated and the simulation results compared with experimental measurements. First the response of the coil without the armature was assessed in order to isolate factors that may influence simulation accuracy. It should be noted that since the FE coil predicted values are susceptible to simulation settings its representation must be kept consistent between simulations once the degree of compensation has been decided. Fig. 4 shows the coil current and capacitor bank voltage for the compensated model and experimental results. As can be seen in Fig. 4 good agreement exists between simulation and experimental results for the coil responses alone. Hence, any subsequent difference should be expected to be related to armature-coil interaction.

In [12] it was shown that for low armature speeds (around $5 \mathrm{~m} / \mathrm{s}$ ) experimental and simulation results are in good 
agreement. However, differences between predicted and measured armature velocity were observed as the armature speed increases. It was argued in [12] that differences in speed may be explained by discrepancies in assumed material elasticity. Therefore, a small diameter armature with a high thickness was used first here in order to reduce armature bending and flexing and thus validate the FE model. Later a higher diameter, thinner armature was employed to assess the effect of bending on the accuracy of the numerical predictions. Since the main thrust of this work was to assess the effects on simulation accuracy with armature speed and flexing, a low speed measurement was used to calibrate armature material resistivity and avoid discrepancies not related to armature flexing. Copper alloy armatures of different material grading were used during the experiments. Fig. 5 shows the armatures employed during experiments and Table 4 lists their physical characteristics. For the simulation the material density was approximated using the armatures' weight and physical dimensions.

Figure 6 shows a comparison between predicted and measured armature speed for the small armature at different capacitor voltages. In the figure, the time axis of measured armature velocity is limited by the high speed camera observable area, varying between measurements depending on armature speed. As can be seen in the figure good agreement exists between measurements and simulations, validating the proposed modelling approach. Next the larger, thinner armature (more susceptible to bending) was used to verify the model accuracy. Fig. 7 shows a comparison of measurement and simulation results for the larger armature. As can be seen in Fig. 7 simulation and experimental results differ as the armature speed increases, which seems to be in line with the suggestion in [12].
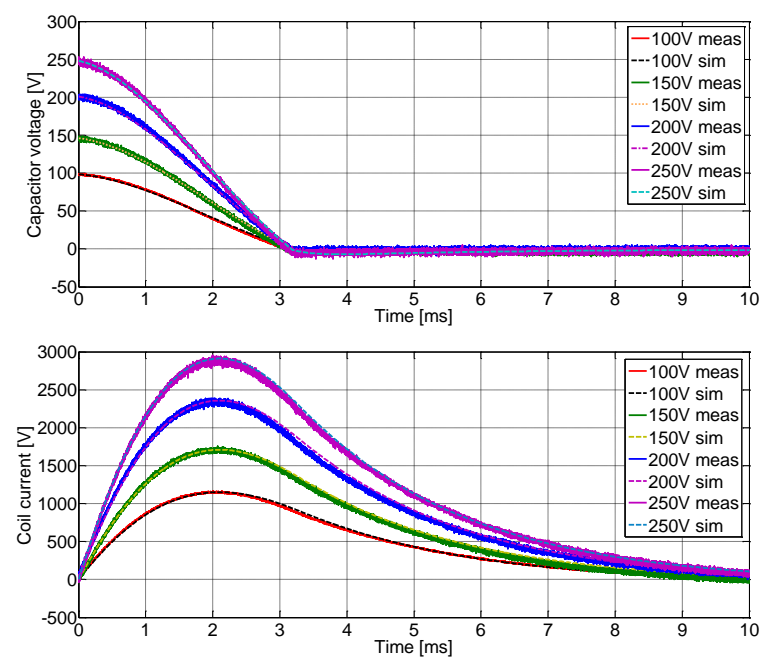

Fig. 4: Experimental vs simulation, coil only response

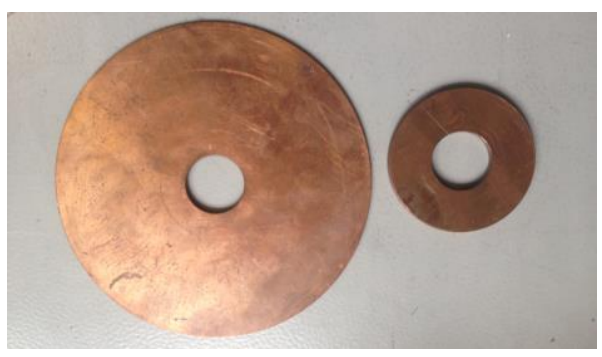

Fig. 5: Copper armatures used during the experiments.

\begin{tabular}{|l|c|c|c|c|c|}
\hline Material & $\begin{array}{c}\text { Thickness } \\
{[\mathbf{m m}]}\end{array}$ & $\begin{array}{c}\text { Inner } \\
\text { radius } \\
{[\mathbf{m m}]}\end{array}$ & $\begin{array}{c}\text { Outer } \\
\text { radius } \\
{[\mathbf{m m}]}\end{array}$ & $\begin{array}{c}\text { Weight } \\
{[\mathbf{g}]}\end{array}$ & $\begin{array}{c}\text { Cond. } \\
\text { IACS } \\
{[\%]}\end{array}$ \\
\hline $\mathrm{Cu}$ alloy & 6.36 & 20 & 50 & 369 & 102 \\
\hline $\mathrm{Cu}$ alloy & 3.29 & 20 & 110 & 1070 & 83 \\
\hline
\end{tabular}

Table 4: Armature characteristics.

However it is also clear from the simulation results that predicted armature speed is centred on the measured speed, instead of diverging from it. Thus simulation results seem to reflect armature mean speed, while the measurements capture armature undulations due to material flexing. To validate this observation a 2D FE model that takes into account material bending (2D-B) is considered below. For the 2D-B FE implementation a linear elastic material is assumed in the simulations and the force acting over the armature is given by (12).

$$
\rho \frac{\partial^{2} u}{\partial t^{2}}-\nabla \cdot S=F
$$

where $S$ is the stress tensor. Simulation results of the 2D-B model are compared with measured armature velocity in Fig. 8. As shown in Fig. 8 simulation and experimental results are in good agreement for the investigated speed range. From the results in Fig. 8 it may be concluded that the speed oscillations observed in the measurements result from armature bending. Thus for a fair assessment, the results of the 2D FE model which neglects armature bending should be compared against armature mean velocity instead. Unfortunately, accurate measurement of armature mean velocity is difficult to obtain, since from the perspective of the high speed camera only the external armature edge is visible. Given the good correlation between the 2D-B FE model and experimental results, a comparison was made between both 2D FE implementations instead. For the comparison, shown in Fig. 9, the armature's mean velocity in the 2D-B model was obtained from the armature's kinetic energy $\left(E_{k}\right)$ using (13).

$$
v=\sqrt{\frac{2 E_{k}}{m}}
$$




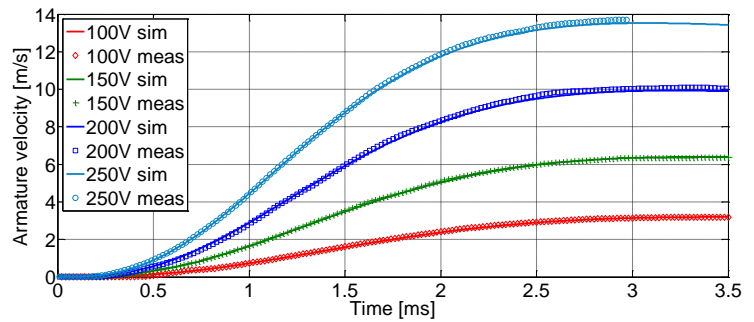

Fig. 6: Small $\mathrm{Cu}$ armature, experimental vs simulation results.

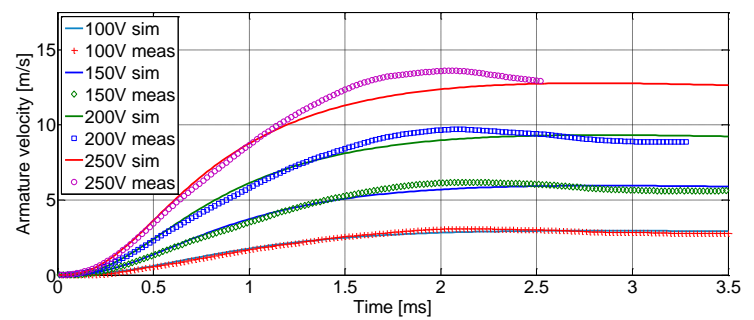

Fig. 7: Large $\mathrm{Cu}$ armature experimental vs simulation results.

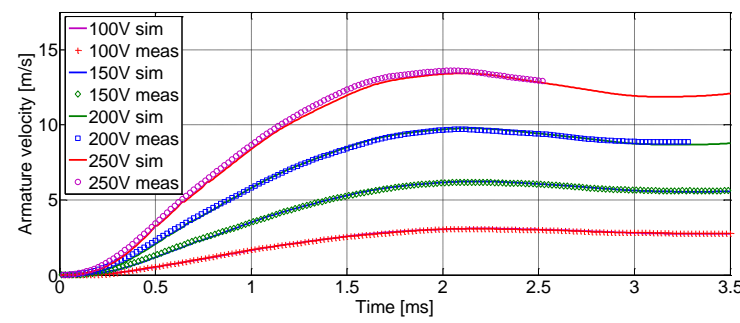

Fig. 8: Large $\mathrm{Cu}$ armature experimental vs simulation results for FE model with bending.

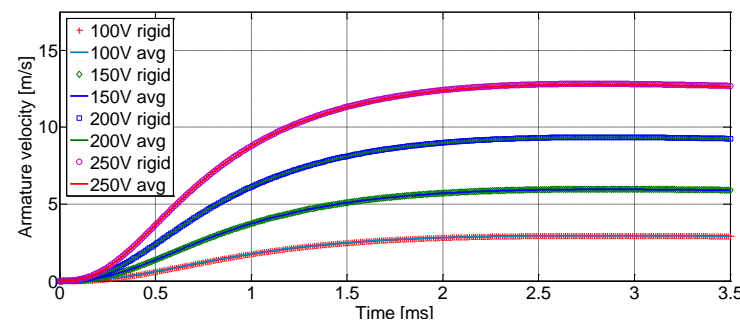

Fig. 9: 2D-B FE model average armature speed vs predicted armature speed obtained with the 2D model considering an infinitely rigid armature.

As shown in Fig. 9, mean armature speed is similar between the two FE implementations, with and without armature bending being considered. Thus even the simpler FE implementation can be used for accurate prediction of armature mean speed. Furthermore, it was found during this research that variations in the armature material's Young's modulus and Poisson's ratio, which define material elasticity, mostly affected the speed oscillations amplitude and frequency rather than armature mean velocity. Even more, large variations of these parameters were required to produce clear differences. On the other hand it was found that variations in the material conductivity have a more significant effect on the armature's mean speed.
To corroborate the accuracy of the FE model at higher armature speeds a lightweight small, thin, aluminium armature was used in the experiments. The armature characteristics are listed in Table 5. Comparison between speed measurements and simulation predictions are shown in Fig. 10. As can be seen in Fig. 10 the model is able to predict with good accuracy the armature behaviour for an armature velocity in excess of $20 \mathrm{~m} / \mathrm{s}$, thus validating the modelling approach. For this armature similar results were obtained with both FE implementations, thus no noticeble bending occurs.

\section{Conclusions}

In this paper the accuracy of a 2D FE axis-symmetric model with passive compensation of the TC model is investigated. It was found that the common assumption of axis-symmetry of the coil can result in important differences between the model and the physical device. Passive inductance and resistance compensation of the axis-symmetric model was shown to allow an accurate representation of the physical device behaviour. It was also found that the asumption of an infinitely rigid armature material may result in discrepancies between measured and predicted armature velocity, mostly related to armature flexing not being considered in the model. When armature flexing is considered in the FE model, numerical predictions and speed measurement show good agreement. Furthermore, the armature speed predicted by the 2D FE model that neglects armature bending was found to be similar to the mean armature speed predicted by the more complex 2D FE model that includes armature bending effects. A lightweight aluminium armature was used to show that no significant differences exist between model predictions and measurements at high speed operation. Reported differences between measurements and FE simulations in armature mean speed may be rather related to variations in assumed and actual armature material electrical conductivity.

\begin{tabular}{|l|c|c|c|c|c|}
\hline Material & $\begin{array}{c}\text { Thickness } \\
{[\mathbf{m m}]}\end{array}$ & $\begin{array}{c}\text { Inner } \\
\text { radius } \\
{[\mathbf{m m}]}\end{array}$ & $\begin{array}{c}\text { Outer } \\
\text { radius } \\
{[\mathbf{m m}]}\end{array}$ & $\begin{array}{c}\text { Weight } \\
{[\mathbf{g}]}\end{array}$ & $\begin{array}{c}\text { Cond. } \\
\text { IACS } \\
{[\%]}\end{array}$ \\
\hline $\mathrm{Al}$ alloy & 2.88 & 20 & 50 & 51 & 40 \\
\hline
\end{tabular}

Table 5: Aluminium armature characteristics.

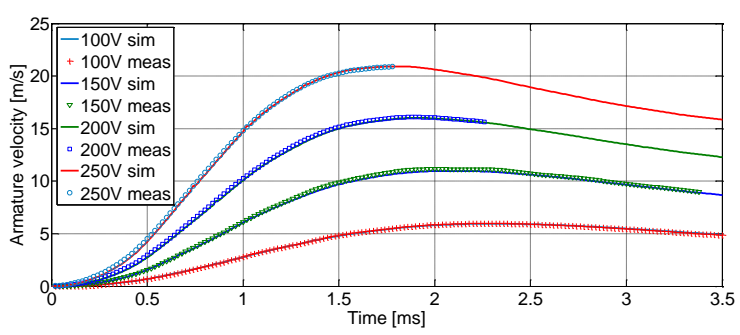

Fig. 10: Aluminium armature velocity, simulation vs experimental. 


\section{Acknowledgements}

This work was funded as part of the UK EPSRC, FCL/B: An Integrated VSC-HVDC Fault Current Limiter/Breaker project, EP/L021552/1.

\section{References}

[1] W. Holaus, K. Frohlich, "Ultra-fast switches- a new element for medium voltage fault current limiting switchgear," Power Engineering Society Winter Meeting, 2002. IEEE, vol.1, no., pp.299,304 vol.1, 2002

[2] W. Wen et al., "Research on Operating Mechanism for Ultra-Fast 40.5-kV Vacuum Switches," in IEEE Transactions on Power Delivery, vol. 30, no. 6, pp. 2553-2560, Dec. 2015.

[3] J. Häfner, B. Jacobson, "Proactive Hybrid HVDC Breakers - A key innovation for reliable HVDC grids," (Cigré Bologna, Paper 0264, 2011)

[4] J. Magnusson, O. Hammar, G. Engdahl "Modelling and Experimental Assessment of Thomson Coil Actuator System for Ultra Fast Mechanical Switches for Commutation of Load Currents," International Conference on New Actuators and Drive Systems, Bremen, 14-16 Jun 2010.

[5] M. Steurer, K. Frohlich, W. Holaus, and K. Kaltenegger, "A novel hybrid current-limiting circuit breaker for medium voltage: Principle and test results," IEEE Trans. Power Del., vol. 18, no. 2, pp. 460-467, Apr. 2003.

[6] W. Li, Y. W. Jeong and C. S. Koh, "An Adaptive Equivalent Circuit Modeling Method for the Eddy Current-Driven Electromechanical System," in IEEE Transactions on Magnetics, vol. 46, no. 6, pp. 18591862, June 2010.

[7] D. K. Lim et al., "Characteristic Analysis and Design of a Thomson Coil Actuator Using an Analytic Method and a Numerical Method," in IEEE Transactions on Magnetics, vol. 49, no. 12, pp. 5749-5755, Dec. 2013.

[8] W. Li, Z. Y. Ren, Y. W. Jeong and C. S. Koh, "Optimal Shape Design of a Thomson-Coil Actuator Utilizing Generalized Topology Optimization Based on Equivalent Circuit Method," in IEEE

Transactions on Magnetics, vol. 47, no. 5, pp. 12461249, May 2011.

[9] M. T. Pham, Z. Ren, W. Li and C. S. Koh, "Optimal Design of a Thomson-Coil Actuator Utilizing a Mixed-Integer-Discrete-Continuous Variables Global Optimization Algorithm," in IEEE Transactions on Magnetics, vol. 47, no. 10, pp. 4163-4166, Oct. 2011.

[10] Y. Wu et al., "A New Thomson Coil Actuator: Principle and Analysis," in IEEE Transactions on Components, Packaging and Manufacturing Technology, vol. 5, no. 11, pp. 1644-1655, Nov. 2015.
[11] A. Bissal, E. Salinas, G. Engdahl, and M. Ohrstrom, "Simulation and verification of Thomson actuator systems," in Proc. COMSOL Conf., Paris, France, 2010, pp. 1-6.

[12] A. Bissal, J. Magnusson, G. Engdahl, "Electric to Mechanical Energy Conversion of Linear Ultrafast Electromechanical Actuators Based on Stroke Requirements," Industry Applications, IEEE Transactions on , vol.51, no.4, pp.3059,3067, JulyAug. 2015.

[13] D.S. Vilchis-Rodriguez, R. Shuttleworth, M. Barnes, "Finite element analysis and efficiency improvement of the Thomson coil actuator", 8th IET International Conference on Power Electronics, Machines and Drives (PEMD 2016), Glasgow, UK, 19-21 April 2016.

[14] H.A. Wheeler, "Formulas For the Skin Effect", Proceedings of the I.R.E., pp. 412-424, Sept. 1942. 